Article

\title{
An Analytical Framework to Study Multi-Actor Partnerships Engaged in Interactive Innovation Processes in the Agriculture, Forestry, and Rural Development Sector
}

\author{
Evelien Cronin ${ }^{1, *} \mathbb{C}$, Sylvie Fosselle ${ }^{1}$, Elke Rogge ${ }^{1}$ and Robert Home ${ }^{2} \mathbb{D}$ \\ 1 Flanders Research Institute for Agriculture, Fisheries and Food (ILVO), 9820 Merelbeke, Belgium; \\ sylvie.fosselle@ilvo.vlaanderen.be (S.F.); Elke.Rogge@ilvo.vlaanderen.be (E.R.) \\ 2 Department of Socioeconomics, Research Institute of Organic Agriculture (FiBL), 5070 Frick, Switzerland; \\ robert.home@fibl.org \\ * Correspondence: Evelien.Cronin@ilvo.vlaanderen.be
}

check for updates

Citation: Cronin, E.; Fosselle, S.; Rogge, E.; Home, R. An Analytical Framework to Study Multi-Actor Partnerships Engaged in Interactive Innovation Processes in the Agriculture, Forestry, and Rural Development Sector. Sustainability 2021, 13, 6428. https://doi.org/ $10.3390 /$ su13116428

Academic Editor: Claus G. Sørensen

Received: 10 May 2021

Accepted: 2 June 2021

Published: 5 June 2021

Publisher's Note: MDPI stays neutral with regard to jurisdictional claims in published maps and institutional affiliations.

Copyright: (C) 2021 by the authors. Licensee MDPI, Basel, Switzerland. This article is an open access article distributed under the terms and conditions of the Creative Commons Attribution (CC BY) license (https:/ / creativecommons.org/licenses/by/ $4.0 /)$.

\begin{abstract}
Communities of practice (CoPs) interact with a range of external stakeholders who collectively influence the direction of the community and the achievement of its goals. In the case of multi-actor co-innovation partnerships, which are perceived as a type of combination between a community of practice and innovation network in this paper, internal and external interactions consequently influence the ability of these partnerships to co-innovate. The aim of this contribution is to develop an analytical framework to understand the factors and processes that enable or hinder interactions, both within and external to multi-actor co-innovation partnerships. The analytical framework was built around interactions with funding mechanisms, external stakeholders, the context/environment, and societal challenges, along with interactions within the partnership. Each of these five interactions is influenced by structures and capacity, along with how these combine to overcome the challenges faced by the partnership. For this study, 30 case study multi-actor co-innovation partnerships from across Europe were selected and analysed according to the framework. The results show that interactions with funding bodies can lead to partnerships adapting to what they perceive to be the goals of the funding body, and sometimes to the overpromising of expected outputs in an effort to win scarce funding. The reflection of societal needs in the goals of funding bodies could thereby capitalize on the motivations and aspirations of partnerships to combine socio-economic and environmental benefits at both individual and societal levels. Factors that enable partnerships to achieve their own goals are commonly based around the inclusion or recruitment of experienced partners with existing networks, in which the partnership may be embedded, that can facilitate internal collaboration and navigate the external environments, such as political structures and market conditions.
\end{abstract}

Keywords: communities of practice; innovation networks; interactions; co-innovation partnerships; innovation; analytical framework

\section{Introduction}

Farmers in Europe are under pressure to innovate, and, for many, this pressure is existential, so business as usual is not a viable strategy for the future of their farms. The authors of [1] reviewed the extensive literature on land-use change and concluded that European farmers are increasingly forced to choose between maximizing the production potential of their farmland or selling it to land investors. The ability of a farmer to adapt to changing conditions and maintain their agricultural activities, that is, their resilience, is not clearly related to farm type but rather depends on the creativity, mental agility, diversity of skills, and the ability of the farmer to repurpose or reallocate resources, explore possibilities, and keep options open [2]. This demonstrates a connection between resilience and the ability to innovate, such as by finding ways to enhance efficiency by improving nutrient 
and carbon cycling [3] or by diversifying farm activities and creating multiple income streams [4]. Farmers who wish to innovate face an array of challenges because they need to implement something that is, by definition, new to them, and for which they may not have the adequate knowledge or skills, while remaining within the technical, agronomic, and socio-economic boundaries [5].

Decision-makers-in this case, farmers-tend to reduce complexity to manageable levels by adopting individual problem perspectives that are informed by a combination of their knowledge and experience and framed by their situational interest [6]. The complexity of the challenges faced by individual farmers when implementing on-farm innovations can lead to operational blind spots in which they find an adequate solution and cease to look for further ways to adapt and improve their production systems. The authors of [7] provide a solution by pointing out that collaboration is a necessary condition for innovation, so approaching innovation without adequate support networks is suboptimal. An alternative way of addressing the challenge of innovation is to join or create a community of practice $(\mathrm{CoP})$ or an innovation network in which a joint reflective learning process can be followed to facilitate the identification of barriers and lock-ins and to support social learning and the co-creation of knowledge.

Although the particular term "communities of practice" is relatively recent, [8] point out that collaborative co-learning and knowledge creation are deeply ingrained in human nature. The CoP approach understands learning as a social activity, in an ongoing collaboration or partnership, in which the adoption of new practices is a process that is driven by a combination of technical and socio-cultural factors $[9,10]$. Learning within a CoP is an outcome of exchange and collaboration in which new knowledge is continuously created that has value and meaning to the collaborators, who share ownership of the new knowledge [11]. In addition to learning and the co-creation of knowledge, CoPs focus on interactions and collective processes that "produce and reproduce discourses and norms providing a framework for individual actions, that both can hamper or support innovation" [12], p. 122. The collective identity of a CoP is defined by its shared domain of interest, so the membership of the community implies an investment of interest in the domain along with a willingness to share competencies, engage in joint activities and discussions, provide support, and share information [11]. CoPs are thereby characterized by interactions and relationships that enable partners to learn from and with each other [8].

However, collaboration alone is not a sufficient condition to ensure successful innovation because innovation outcomes are mediated by social performance, which is related to the cultivation of an environment for external knowledge acquisition and transformation in order to accommodate the application of innovative products, practices, or processes [7]. In the case of a CoP that exists to enable farmers to find and apply innovative practices to enhance the resilience of their farms within the agricultural system with its complex supply chains, there is an implication that communities of practice will need to interact externally [12].

In this paper, the focus lies on a particular type of CoP: "multi-actor co-innovation partnerships". While a CoP is commonly categorised as an informal learning community amongst peers, also more formalised formats of cooperation can meet the characteristics commonly used to describe a $\mathrm{CoP}$ [12]. In this contribution, we focus on those collaborations that are multi-disciplinary and intersectoral; multi-actor co-innovation partnerships can be conceptualised as a social learning system where interactions take place in which members develop a shared practice over time via a shared repertoire of communal resources. Furthermore, the understanding of co-innovation, in line with [13] and [14] as a process in which multiple partners manage mutual knowledge flows across their organisational boundaries through joint activities while engaging actors in iterative learning processes, is congruent with activities performed by CoPs, as described by, for example, [12]. However, as CoPs are mostly defined as actors with similar characteristics (e.g., farmers), multi-actor co-innovation partnerships appear to fall in a conceptually fuzzy area between 
a CoP and an innovation network, which is more often understood as multi-disciplinary and intersectoral cooperation.

Although multi-actor co-innovation partnerships are reasonably common in Europe, with more than 1300 identified by [13,15], there is insufficient understanding of how they work and, above all, how they might be supported in their efforts to enhance the development and implementation of innovation (or innovative practices). This suggests the value of a comparative analysis to identify the factors that enable or hinder their success. However, a major challenge to the analysis of the functioning of multi-actor co-innovation partnerships is the difficulty in finding enough common ground to compare the wide diversity of these types of partnerships and to initiate a learning process that goes beyond the particularities of individual cases. By conceptualising these partnerships as collaborative structures falling in between CoPs and innovation networks, we aim to draw upon and bring together a multi-disciplinary body of pre-existing knowledge while creating a common conceptual starting point for their analysis.

The aim of this contribution is therefore to develop and pilot an analytical framework that has the potential to enable comparison and thereby facilitate generalizations as to the factors that support or hinder the success of the partnerships. In this paper, we develop and explain an analytical framework with three objectives: (1) to facilitate the collection and analysis of data when studying multi-actor co-innovation partnerships; (2) to gain and ensure a common understanding of key concepts and relevant issues for studying multi-actor co-innovation partnerships; and (3) to build a basis for comparison between different types of multi-actor co-innovation partnerships. Piloting the analytical framework will give insight into the applicability of the analytical framework as a tool to support dialogue and reflection during the evaluation of multi-actor co-innovation partnerships, while also identifying common enablers and barriers to their success.

\section{Bringing Structure to the Complexity of Multi-Actor Partnerships: Developing an Analytical Framework}

Much of the research on CoPs, and particularly on innovation networks, has focussed on how actors collaborate and reflect on their collaboration, and how participants interact with facilitators $[16,17]$. However, these studies have also identified the most important barriers to reaching the potential of innovation networks or CoPs, which includes a lack of funds, horizontal and vertical fragmentation, and a lack of adequate evaluation criteria for reflecting on practices [18]. This suggests that evaluation criteria should include an examination of any horizontal and vertical connectivity along with the success or otherwise in securing funding, which implies that analyses of innovation networks or CoPs- and thus, also multi-actor co-innovation partnerships-should include the analysis of the external, as well as the internal, interactions.

The authors of [19] found that factors at three contextual levels-environment, network, and actor-influence management activities in innovation networks, but this finding refers primarily to internal activities within a network rather than institutional interactions by the innovation network (or representatives). However, multi-actor co-innovation partnerships also need interactions beyond their own group to reach their objectives [13]. The authors of [20], p. 9 point out that "farming system research focuses on systems taken as a whole, i.e., it is concerned with total-system performance, not least because 'optimizing' individual parts tends to have undesirable side effects elsewhere in the system and therefore tends to come at the cost of the performance of the overall system". Taking a "farming systems" perspective implies that in order to fully understand and assess the processes of co-innovation in multi-actor partnerships, we need to look at the wider (farming or agricultural) system in which they are embedded. By including the wider environment or ecosystem that multi-actor co-innovation partnerships operate in, we link partnerships ${ }^{\prime}$ internal activities to more institutional interactions and other partnerships, thus moving beyond the focus on just one level in order to get meaningful insights for the improvement of co-innovation processes by looking at the system as a whole. 
The author of [21] described local professional groups, which are analogous to CoPs, according to criteria concerning sources of innovation (unique/diverse, internal/external), interactions (the capacity to exchange with the other groups of actors outside a CoP), and dialogue (the way the choices are justified; the type and the quality of argumentation). The author of [12] expanded on this to propose an analytical framework to analyse CoPs in the environment of innovation projects and their role in the innovation process. The author of [12]'s framework was built around interactions between actors within an innovation project, their sources of knowledge, and discourses they reproduce in relation to their actions but also recognizes interactions by members with actors or institutions outside the project. Indeed, the typology of CoPs they produced includes distinctions based on the connectedness with external actors [12]. Given that the ability of multi-actor co-innovation partnerships to function is mediated by social performance, an analytical framework must consider the embeddedness in the external environment, its relation to other relevant actors outside the partnership, and its potential long-term effect $[7,14]$.

Although [12]'s framework recognizes interactions and connections outside a project, they do not differentiate between different types of external actors or institutions. We propose that the form and function of interactions with external actors may be different, with different requisite skills to facilitate the interactions. Consequently, such a distinction is valuable in gaining an understanding of the factors and processes that enable the success of multi-actor co-innovation partnerships. We, therefore, elaborate on the findings of [12] and propose an analytical framework that differentiates between interactions with funding mechanisms, other projects or stakeholders, the contextual environment, and societal challenges, in addition to the interactions within a partnership.

\subsection{Funding Mechanisms}

While the lack of funding has been recognized as an important barrier to innovation networks [18], the questions relating to how these networks gain access to funding, why some succeed better in fund acquisition, and the impact of a specific type of funding, are often only superficially answered. Many multi-actor co-innovation partnerships seek external funding at the local, national, or European level, with the initiators seeking to find a way of financing the cooperation at an early stage of the establishment of the partnerships or to ensure the consolidation of their network [17]. Moreover, competition for scarce resources is high, and, as many partnerships seek public funding, the role of policy and government actors, who set the agenda and draft overarching policy strategies and objectives, come to the fore [18]. Policies, programs, and governance arrangements can operate as a filter that influences the framework conditions for any innovation process to unfold, and which potentially assists the "institutional anchoring" of certain types of innovation at the expense of others [22]. More specifically, policy and government actors decide which themes are put on the agenda and which initiatives eventually attain policy attention and support. The same logic applies to private funding. Both government and private funding decisions are made by comparing the goals of the project with the goals of the funder so that proposals in which the goals are not aligned are unlikely to be funded. The authors of [23] point out that applicants develop a range of strategies, such as directing projects into areas that funding bodies would deem useful, highlighting expected outputs, and adopting market-based terminology, to enable them to maintain their critical focus, despite increasing pressures to conform to institutional agendas. The authors of [18] also identified this, along with the volatility of topics, as an effective barrier to long-term support as political agendas change. This implies that innovations or multi-actor partnerships that fit well within the current policy agenda or programme objectives might be selected for public funding more easily, while more radical or less mainstream innovations might be perceived as too risky and thus, be overlooked. 


\subsection{Interaction/Networking with External Stakeholders}

The proposition that the performance in goal achievement of innovation networks can be enhanced by encouraging active networking among dispersed communities has been long-established [24,25]. There is indeed a broad consensus on the mutual advantages, or even necessity, of knowledge sharing across social communities in a community-based model of knowledge management for interactive innovation [24,26]. The authors of [27] point out the importance of understanding the dynamics of innovation networking and continue to note that these dynamics are under-researched, particularly at the local level. The authors of [27] further comment that, while external knowledge is significant for novel innovation, and that local network embeddedness has a particular function, the ways in which a co-innovation partnership interacts with other, sometimes competing partnerships, must be adapted to the particular circumstances. It is problematic to uncritically adopt dominant ideas developed in other contexts about how such interactions should be structured, and alternative views of how partnerships learn and innovate need to be considered in conceptual frameworks [28]. This need highlights the importance of giving separate consideration to such interactions in an evaluation of a multi-actor co-innovation partnership because assumptions based upon the simple transposition of these dominant ideas on the structure of interactions to other contexts may simply be wrong [27].

\subsection{Interaction with the Context/Enabling or Disabling Environment}

The performance of multi-actor partnerships for innovation has been observed not only to depend on the dynamics of the innovation process but also on the specific socioeconomic and agro-ecological contexts [29,30]. The authors of [18] also argue that the structural conditions related to both formal and informal institutions can effectively hinder or incentivize learning and collaboration, and they stress that the volatility of political attention and support can have a detrimental impact on innovation processes in creating space for innovation and innovative practices. Furthermore, [31] found that "interactions occur in the context of various institutional arrangements [...], which affect how the actors pursue their interests and ideas and the extent to which their efforts succeed." This raises questions about how different institutional, social, and cultural contexts governing coinnovation and social learning can be accommodated [14]. Co-innovation processes are thus embedded in different contexts and this context matters [30,31]. There is also a duality to be considered here: namely that innovation processes are influenced by the context, yet that context is also influenced by the interactive innovation processes. Reference [31], p. 11 pointed out that "as ideas are institutionalized, they become the foundation for shaping (allowing and/or constraining) the context in which future policy choices are made." CoPs and innovation network actors continuously interact with and re-interpret their contextual environment because the innovation process is affected by unintended consequences of actions and random events [32].

We have defined this "context" as consisting of the enabling or disabling environment, which includes the level of acceptance or openness of a specific context towards innovations, innovative ideas, and new ways of cooperation, and which constitutes both formal and informal environments. The formal regulatory environment includes legislation that is changed or adopted in support of innovation or innovative ideas, specific types of tax incentives or subsidies, and the creation of public supporting structures, such as national contact points. The informal environment includes social factors, such as norms, values, and different types of capitals, which create the available "mental space", the willingness to support a different way of working, or a shift or evolution in beliefs, values, and norms.

\subsection{Interaction with the Societal Challenges}

Following [31], p. 10 we can wonder whether "innovation is transformed from a means to achieving a broad range of public policy goals into a policy goal for a broad range of public policy domains." Although this interaction is particularly relevant to publiclyfunded multi-actor co-innovation partnerships, the number of such networks and the 
concept of corporate social responsibility support the value of including interactions with societal challenges in the analytical framework [13,33]. Furthermore, as the European Commission has made a decision to largely reach its societal objectives via the implementation of projects, the question remains whether, and how, this diverse range of projects will impact the societal objectives or challenges [34]. This implies the need to understand whether there is any form of policy learning: When the multi-actor co-innovation partnerships are finalized or have reached their objectives, what do policymakers actually take from them?

\subsection{Five Types of Interactions}

These four types of interactions, combined with the interactions within multi-actor co-innovation partnerships that are well established in the literature $[16,17]$ to produce five identifiable types of interaction, are shown in Figure 1.

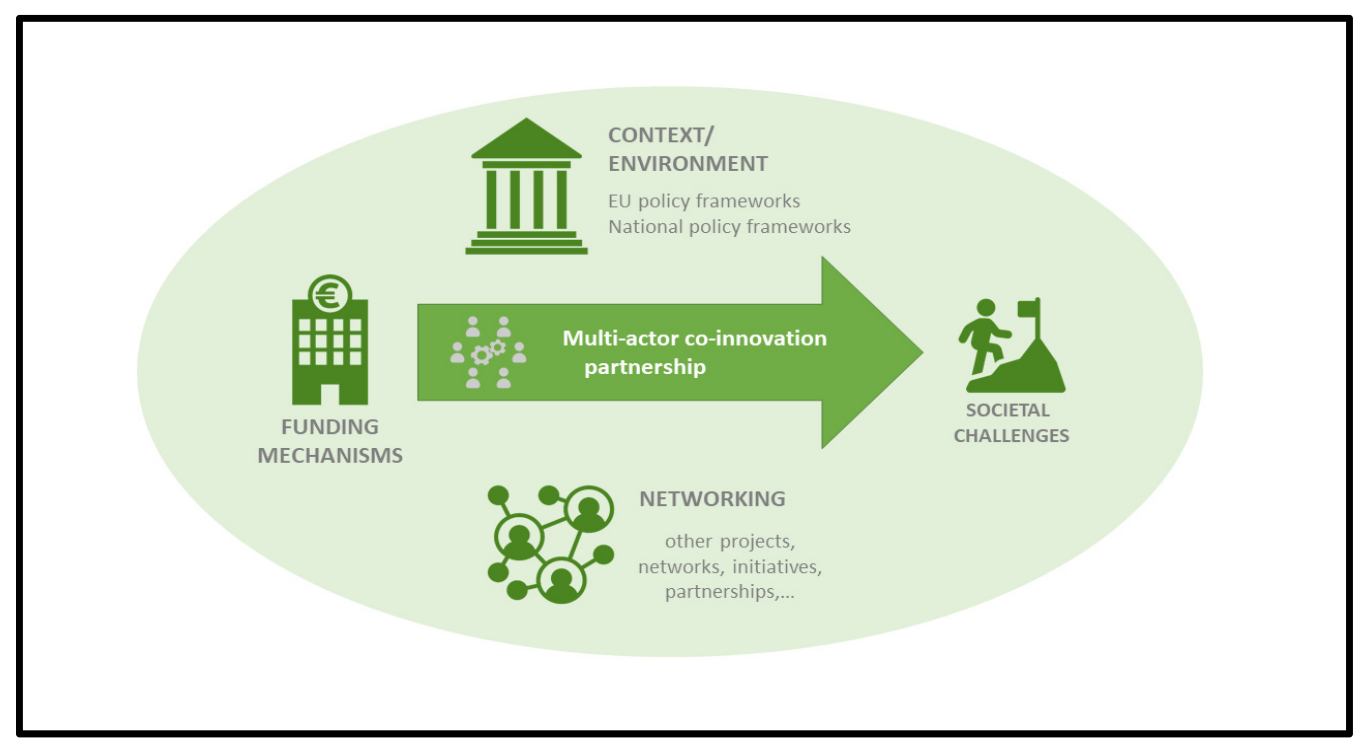

Figure 1. Visual representation of the five interactions analytical framework.

However, a further layer of the analytical framework is needed to understand the interactions, so, based on the results of [35,36], we included the examination of each interaction through the lenses of "structure" and "capacities" within the analytical framework. The "structure" lens refers to how organizations, in this case, multi-actor co-innovation partnerships, align their activities with their objectives, such as by establishing open innovation processes and specialized innovation teams or by creating an organizational culture that can be interpreted as the "rules of the game" or the "code of conduct" $[13,37,38]$. The authors of [39] (p. 117) remind us that structures in the context of innovation systems are created with the intention of facilitating the partnership to perform the functions of overcoming challenges and attaining objectives, such as "learning and knowledge cocreation, upscaling and institutional entrepreneurship, and outscaling and innovation brokerage". Partnerships must therefore either possess or have access to the capacities to implement the structures and perform these functions, which suggests the need for including a "capacities" lens to evaluate enabling factors, such as available resources, skills, and competencies $[35,36,39]$. The author of [40] notes that the key to understanding the success of interactive innovation is to consider both opportunity and the process through which a partnership has created innovation through the cultivation and leadership of a network of players with different and complementary skills. A similar combination of structures and capacities to enable the function of networks was proposed by [41] in the context of multi-stakeholder forums, which share many of the characteristics of multi-actor co-innovation partnerships $[13,15]$. We, therefore, added a third lens to the analytical framework that we call "overcoming challenges", which refers to how the capacities and structures combine to enable the partnership to overcome identified challenges. 


\section{Materials and Methods}

An initial pool of 200 European multi-actor co-innovation partnerships in the agriculture, forestry, and rural development sector was identified within the EU H2020 research project LIAISON [13,15] and contacted by phone for a screening interview. This initial pool of 200 partnerships was selected based upon 4 criteria, including (a) being a multi-actor partnership, meaning being composed of two or more entities, (b) having a clear intention to innovate in (c) a relevant topic, and (d) featuring an engagement with practitioners.

From this pool, 30 case studies were selected based on the willingness of the partnership's coordinator to participate as a case study, the geographical coverage, and the type of co-innovation partnership. In addition to these practical considerations, the key selection requirement was that the partnership must be "truly multi-actor", relating to the (a) degree of cooperation, collaboration, and co-creation, (b) the variety of the type of actors within the partnership, and (c) the degree and manner of involvement of the practitioners.

Between January and June 2020, a total of 283 in-depth interviews were carried out with respondents relevant to the selected 30 multi-actor co-innovation partnerships that participated in the LIAISON project (Table 1). Although the analytical framework does not specify the methods for data collection, the data were collected by an individual researcher for each partnership by means of semi-structured in-depth interviews. To contribute to reliability, and an agreed and common understanding of the terms, all researchers took part in a two-day training session prior to data collection. Respondents included actors who are formally part of the partnerships (i.e., "partners"), as well as other stakeholders who had interacted with the partnerships, such as policymakers, farmers, or other societal actors. The respondents were asked to describe the structures and capacities they perceive to have contributed to their success, along with key challenges and how or whether these had been overcome. The responses from each case study were analysed according to their content, with an initial coding in accordance with the analytical framework. The individual coding schemes were then collated for comparison to allow for generalizations about the impacts of interactions on the abilities of the partnerships to succeed in overcoming challenges.

Table 1. Overview of data collection activities in the LIAISON case studies.

\begin{tabular}{|c|c|c|c|c|c|c|c|c|}
\hline Code & Funding Type & No. of Interviews & Code & Funding Type & No. of Interviews & Code & Funding Type & No. of Interviews \\
\hline $\mathrm{C} 01$ & H2020 & 8 & C11 & $\mathrm{H} 2020$ & 10 & $\mathrm{C} 21$ & Operational group & 13 \\
\hline $\mathrm{C} 02$ & H2020 & 12 & $\mathrm{C} 12$ & Mixed funding & 9 & $\mathrm{C} 22$ & RDP & 17 \\
\hline $\mathrm{C} 03$ & H2020 & 12 & $\mathrm{C} 13$ & Mixed funding & 10 & $\mathrm{C} 23$ & RDP & 15 \\
\hline $\mathrm{CO4}$ & Erasmus+ & 4 & C14 & RDP & 6 & $\mathrm{C} 24$ & RDP & 6 \\
\hline $\mathrm{C} 05$ & H2020 & 12 & $\mathrm{C} 15$ & Mixed funding & 12 & $\mathrm{C} 25$ & Private funding & 8 \\
\hline $\mathrm{C} 06$ & Interreg & 7 & $\mathrm{C} 16$ & National public funding & 9 & $\mathrm{C} 26$ & Private funding & 9 \\
\hline $\mathrm{C} 07$ & Interreg & 16 & $\mathrm{C} 17$ & National public funding & 13 & $\mathrm{C} 27$ & $\mathrm{RDP}+$ private funding & 5 \\
\hline $\mathrm{C} 08$ & Interreg & 5 & $\mathrm{C} 18$ & Operational group & 8 & $\mathrm{C} 28$ & Private funding & 7 \\
\hline C09 & Interreg & 10 & C19 & Operational group & 8 & $\mathrm{C} 29$ & Private funding & 11 \\
\hline $\mathrm{C} 10$ & Life & 11 & $\mathrm{C} 20$ & Operational group & 5 & C30 & Private funding & 5 \\
\hline
\end{tabular}

Legend: H2020 refers to the European Horizon 2020 Research and Innovation Programme. Interreg refers to one of the key instruments of the European Union (EU) to support cross-border cooperation via projects. Life refers to the EU funding instrument in support of the environment and climate action. If the case is described as receiving mixed funding, this means that the partnership combines different public and private funding sources. National public funding implies that the case study secured public funding from a national source. Operational groups are a distinct type of partnership funded at the Member State level via the European Agricultural Fund for Rural Development. RDP refers to Rural Development Programmes and implies that these case studies are implemented in the frame of these national or regional programmes. Private implies that these case studies receive funding from private sources. 
As Table 1 shows, a large share of the sample of 30 multi-actor co-innovation partnerships received support from EU funds or programmes, which is related to the applied sampling approach $[13,15]$. Still, this sample represents a wide diversity in terms of types of multi-actor co-innovation partnerships when looking at (a) the type of entity the partners form, (b) the activities the partnership undertakes, (c) the timeframe in which they are implemented, (d) the overall budget with which they operate, and finally, (e) the type of output or outcome they aim to deliver. Based upon the interviews with different case study respondents, these partnerships were described as projects, programmes, cooperatives, clusters, or even single entrepreneur co-innovation initiatives.

\section{Results and Discussion}

The results of the analysis are organized according to each of the five interactions within the analytical framework, with structures, capacities, and how these combine to overcome challenges, described for each interaction. The codes from Table 1 have been added to each of the factors that were revealed in the analysis to indicate which multiactor co-innovation partnerships mentioned the particular factor in their responses to the interview questions.

\subsection{Interactions with the Funding Mechanism}

Multi-actor consortia seeking funding from a central funding body, such as the EU, face a complicated application process. An enabling structure is the availability of the often significant financial resources required to prepare an application, which were commonly internal within the partners' organizations (C01; C02); although, some applications received seed funding in support of proposal preparation $(\mathrm{C} 04 ; \mathrm{C} 08)$. The necessary human resources were typically available within a consortium but required the careful allocation of tasks according to skills (C01; C04; C18), such as English language ability (C04), writing skills (C04; C09: C10; C11; C19), and the "soft" skills of motivating people from different backgrounds to work together $(\mathrm{C} 01 ; \mathrm{C} 10 ; \mathrm{C} 19)$. Experience contributes to success because the writer (s) better understand what is needed (C01; C09), which funding body is most suited (C07; $\mathrm{C} 08 ; \mathrm{C} 09)$, and/or because a proven history brings trust from the funding body $(\mathrm{C} 04 ; \mathrm{C} 07 ; \mathrm{C} 08 ; \mathrm{C} 11)$. The allocation of skills and acknowledging the need to include experienced writers within the partnership can be understood as a means of navigating the institutional anchoring noted by [22] and ensuring that proposals are presented in a way that matches the organizational culture of the funding body [23].

In some cases, an individual or organization with specific experience in proposal writing was recruited, or external advice sought (C09; C19), which is an understandable response to the competition identified by [18]. Many countries have established contact points that provide advice about the application procedure, although the quality of this advice varies. The role of these contact points is to provide the knowledge of desired institutional terminology that [23] point out is needed to convince funding bodies of the alignment of proposed projects with mainstream institutional thought. Some partnerships reported motivated engagement by client-orientated staff ( $\mathrm{C} 07 ; \mathrm{C} 22 ; \mathrm{C} 24)$, which sometimes proofread applications $(\mathrm{C} 09 ; \mathrm{C} 21)$ and significantly contributed to gaining funding (C09; C27). Others reported poorly resourced contact points with inexperienced staff who were unable to help effectively (C10) or charge excessively for the service, which forced partnerships to seek support through informal networks, such as a regional council (C21) or personal networks of peers (C25). The ability of contact points to complement or provide a substitute for experience within a consortium is clearly an enabling factor, especially for inexperienced applicants.

Partnerships financed by public funding should reflect a societal demand (C26; C27), which means that proposal writers have to predict which societal demand is prioritized. Although many public funding bodies give individual advice about which topics are most relevant (C09; $\mathrm{C} 26)$, the high case loads of advisors means that the advice is often insufficient $(\mathrm{C} 02 ; \mathrm{C} 04)$, leading to uncertainty about how to align the goals of the partners with 
the specific societal needs (C12; C23; C29). Funding bodies were, however, usually clear on the process, although inflexibility was nominated as a hindrance for interactive innovation. While transparent rules are appreciated, there is a perception that administrative requirements, such as co-financing (C06), favour the inclusion in consortia of established, wealthy organisations (C19) over smaller and newer organisations (C06; C10), which are often more dynamic and innovative (C27) but unable to fulfil inflexible administrative requirements (C06; C08; C10).

Funding bodies are usually inflexible to deviations from proposed work plans, which restricts the adaptability of the innovation project in response to internal and external stimulation (C01; C10; C12; C26), and thereby stifles creativity (C04), narrows objectives (C14), adds costs (C30), and inhibits departing from current industry practices (C12; C24). These are precisely the restrictions that require a strategic application of resources to make sure that applications are expressed in a language compatible with the funding bodies, such as in terms of measurable outputs and market-based terminology [23]. Funding bodies often demand quantifiable projected outcomes, which are particularly difficult for new topics, but are included in proposals, even when they are known to be unrealistic (C07; C08; C11). The perceived inflexibility of public funding leads to some innovation projects seeking funding elsewhere, such as in the private sector, which is less risk-averse because risk is associated with reward (C24) [42].

Funding applications are commonly submitted in response to a call for proposals, which means that funding bodies can choose which project content will be funded (C18). In response to this restriction, proposal writers adapted the projects they propose to align with what they predicted would be desired by the funders (C01; C05; C13), which is the strategy that [23] identified in their study. The results of such adaptation were that projects were guided by funding calls and formal requirements rather than by the ideas and goals of the participants or to serve the needs of the end-users (C08; C09; C10; C22). Adaptation also led to over-promising to win funding (C04) in the competitive funding environment [18], a practice that could potentially lead to projects not being able to deliver what they promise, and which could have a negative effect on trust in the future.

On the other hand, the need to fulfil their formal and administrative requirements can lead to opportunities. For example, requirements to consider the geographical distribution of project partners led to networks being established that might not have otherwise formed (C03; C04) and requirements for co-funding led to engagement by actors such as regional authorities (C08; C12). Support by public funding bodies could also lead to a perception that a project or partnership is "worthwhile" (C15; C16), which in turn can lead to private sector support (C13). Furthermore, the need to fulfil formal requirements sometimes led to improvements in the project design $(\mathrm{C} 15 ; \mathrm{C} 16)$, such as one project that was required to create a business plan/profitability study that was later a key to its success (C17). An overview of the key findings with regard to interactions between funding mechanisms and multi-actor co-innovation partnerships is shown in Table 2.

Table 2. Overview of key findings for interactions with the funding mechanism.

\begin{tabular}{llll}
\hline Main Findings & Enabling Structures & Functions/Challenges & Overcoming Challenges \\
\hline & $\begin{array}{l}\text { Financial resources in partner } \\
\text { institutions to prepare }\end{array}$ & $\begin{array}{l}\text { Uncertainty about policy } \\
\text { apjectives of funding bodies. }\end{array}$ & $\begin{array}{l}\text { Project applicants adapt } \\
\text { projects to fit with perceived } \\
\text { policy objectives of funding } \\
\text { bodies. }\end{array}$ \\
$\begin{array}{l}\text { Complicated interaction } \\
\text { with a range of formal }\end{array}$ & $\begin{array}{l}\text { sometimes available to finance } \\
\text { applications. }\end{array}$ & $\begin{array}{l}\text { Inflexible formal requirements. } \\
\text { Lack of resources excludes }\end{array}$ & $\begin{array}{l}\text { Over-promising of expected } \\
\text { smaller (but sometimes }\end{array}$ \\
$\begin{array}{l}\text { Funding bodies usually } \\
\text { provide public money in }\end{array}$ & $\begin{array}{l}\text { People skills to motivate } \\
\text { collaboration prior to funding. }\end{array}$ & $\begin{array}{l}\text { dynamic and innovative) } \\
\text { organizations. }\end{array}$ & $\begin{array}{l}\text { outp can win funding but } \\
\text { lead to failure to deliver. } \\
\text { line with policy goals. }\end{array}$ \\
& $\begin{array}{l}\text { Experienced applicant in project } \\
\text { consortium. Can be recruited or } \\
\text { engaged externally. }\end{array}$ & $\begin{array}{l}\text { Innovation is risky and public } \\
\text { funding bodies are }\end{array}$ & $\begin{array}{l}\text { Adation to policy goals can } \\
\text { improve projects and enhance } \\
\text { networks. }\end{array}$ \\
& National and local contact points. & risk-averse. & \\
\hline
\end{tabular}




\subsection{Interactions within the Partnership}

Enabling structures for interactions within multi-actor innovation partnerships were typically built around the competencies of the project coordinator or the core management group. Partnerships are commonly constructed to bring together a group of people with a common interest and complementary skills. In particular, the coordination of a partnership requires a distinct skill set [43]. This specialization and the diversity of specializations was seen as a strength of multi-actor co-innovation partnerships (C01; C03; C04; C06; $\mathrm{C} 10 ; \mathrm{C} 23$ ). One of the common burdens, and particularly with externally funded projects, are administrative requirements [43,44]. These need a specific set of skills, which can remove the load from other partners and enable them to focus on innovation during their interactions (C02; $\mathrm{C} 04 ; \mathrm{C} 07 ; \mathrm{C} 10 ; \mathrm{C} 18)$ [43].

A further role of a partnership coordinator or another key player is to motivate cooperation and ensure that project partners, who may come from very different backgrounds, have roles in the partnership that they feel matches their potential (C06; $\mathrm{C} 07 ; \mathrm{C} 09 ; \mathrm{C} 14)$ in a working environment that is built upon respect and trust $(\mathrm{C} 07 ; \mathrm{C} 08 ; \mathrm{C} 09 ; \mathrm{C} 10 ; \mathrm{C} 20$; C24) [43]. To enable interactions within the case study partnerships, the coordinator or management group commonly made efforts to create structures with the goal of facilitating inclusion $(\mathrm{C} 02 ; \mathrm{C} 03 ; \mathrm{C} 04 ; \mathrm{C} 07 ; \mathrm{C} 08 ; \mathrm{C} 09 ; \mathrm{C} 14 ; \mathrm{C} 16 ; \mathrm{C} 24)$ [45]. There are a wide variety of possible inclusion structures that had been implemented in the case study partnerships, but all were built around the principles of ongoing and frequent communication, equality of voice, openness, and trust. These inclusion structures resonate closely with the standards and quality of interaction within CoPs and the importance of constructing a narrative together, found by [12].

While there was general agreement that diversity of specializations is a strength of innovation partnerships, this was not always easy to achieve in reality due to different degrees of participation [44]. Difficulties in communication, such as due to language and cultural barriers in larger, geographically spread projects (C02), and to participants from different professional worlds, such as foresters, architects, and academics (C09), were identified as challenges to interactions within partnerships. These communication challenges were exacerbated as partnerships grew and struggled to maintain their identity as new partners joined, which meant that continual efforts to motivate team creativity were needed (C26).

A further challenge as partnerships proceed is how to maintain the interest and engagement of partners who can easily become non-participants, particularly if the partners lacked ownership and felt they were contributors to somebody else's project (C02; $\mathrm{C} 03$; C05) $[43,44]$. This reflects the findings of [11], who point out that feelings of ownership of the process and new knowledge are essential for maintaining participant engagement in CoPs. Ownership was usually claimed by the core group who initiated the partnership, and conscious efforts were needed to motivate continued engagement by recruited partners, especially in larger partnerships (C02; C07; C15). As [43], p. 13 points out, partnership leaders provide the mental models to integrate divergent and convergent thinking, deal with "different iterations and loops in the innovation process", encourage wild ideas and "stimulate out-of-the-box thinking". In some cases, a reluctance to participate was related to self-perceptions of competencies, such as farmers being unaccustomed to interacting within structures that had been created by academic partners and which were based on interactions within the academic world (C01; C06). The process and added value of complementing farmers' knowledge or practices with scientific validation or the feeling of it being included in the scientific narrative forms an essential foundation for continued engagement in CoPs [11]. This was shown in other cases, where partners were able to adapt their practices and roles according to the new interactive environment, which appears to be largely due to the skills of the coordinator, or coordination team, in creating appropriate inclusive structures (C04; $\mathrm{C} 05 ; \mathrm{C} 14 ; \mathrm{C} 20 ; \mathrm{C} 23)$.

The usual means of creating a partnership with a diversity of specializations that combine to collaborate and maintain engagement over an extended period is to select 
partners with common interests and goals (C01; C05; C08; C11; C14; C16; C19; C20). In some cases, respondents reported having selected partners based on previous friendly collaborations, which enabled a positive group dynamic (C02; C03; C11), while others reported difficulties in collaborating with "strangers" with whom insufficient trust had been built (C06; C10; C15). Indeed, building personal and institutional trust was commonly nominated as a key means of overcoming challenges to interactions within a partnership (C10; C11; C14; C15; C17; C24; C25; C27).

However, the means with which trust was built varied greatly between cases, but always takes time and must always be appropriate to national (C09; C14) as well as organizational (C10; $\mathrm{C} 14 ; \mathrm{C} 24)$ cultures. The reputation of the partner within the industry or sector both eased the process of gaining trust and enabled appropriate means to be chosen based on their experience (C09; C25; C27; C25). Once mutual trust had been generated, respondents reported that they had created an environment that facilitated co-learning and reflection (C02; C03; C04; C20), which, with skilled facilitation, built trust further. This iterative process of learning, reflection, and trust-building was perceived to be a key enabler of the innovation process (C02; C03, C04; C05; C05; C07; C10; C11; C23). An overview of the key findings with regard to interactions within multi-actor co-innovation partnerships is shown in Table 3.

Table 3. Overview of key findings for interactions within the partnership.

\begin{tabular}{|c|c|c|c|}
\hline Main Findings & Enabling Structures & Functions/Challenges & Overcoming Challenges \\
\hline $\begin{array}{l}\text { Multi-actor co-innovation } \\
\text { partnerships bring together } \\
\text { people with common interests } \\
\text { and complementary skills. } \\
\text { Partners typically come from } \\
\text { a range of professional } \\
\text { backgrounds and sometimes } \\
\text { different cultural } \\
\text { backgrounds. }\end{array}$ & $\begin{array}{l}\text { Facilitation skills of the } \\
\text { coordinator or coordination } \\
\text { group. } \\
\text { Specific inclusion structures } \\
\text { built around the principles of } \\
\text { ongoing and frequent } \\
\text { communication, equality of } \\
\text { voice, openness, and trust. }\end{array}$ & $\begin{array}{l}\text { Communication difficulties } \\
\text { because of language, cultural } \\
\text { background, or professional } \\
\text { background. } \\
\text { (Lack of) ownership of the } \\
\text { partnership leading to } \\
\text { disengagement. } \\
\text { Self-doubts about abilities to } \\
\text { work within a multi-actor } \\
\text { partnership, which for many } \\
\text { partners is new. }\end{array}$ & $\begin{array}{l}\text { An iterative process of } \\
\text { co-learning, reflection, and } \\
\text { trust-building over time. } \\
\text { Facilitation skills of the } \\
\text { coordinator or coordination } \\
\text { team. } \\
\text { The reputation and implied } \\
\text { authority of the coordinator } \\
\text { eases the process of } \\
\text { co-learning, reflection, and } \\
\text { trust-building. }\end{array}$ \\
\hline
\end{tabular}

\subsection{Interactions with External Stakeholders}

Interacting with external stakeholders and other partnerships is analogous to networking, so explicit network coordination was a commonly found enabling structure. The organization of the networking was typically top-down "embeddedness by design" (C22; C23; C25; C26) and sometimes followed a requirement by the funding body (C07; C09; C22; C23). In other cases, the networking coordination structures were suggestions for cooperation, or even voluntary, and driven by the partnerships' coordinator or coordination team (C02; C04). Networking with external stakeholders was facilitated in many cases by existing multi-actor platforms, such as online forums (C02; C04) and/or formal networks or associations $(\mathrm{C} 11 ; \mathrm{C} 16)$. The focus given to networking structures reflects the results of [25], who found that active networking among dispersed communities enhances the performance of goal achievement of co-innovation networks.

Another important external interaction is with end-users of the innovations, which means that feedback structures are needed. A range of tools was created to gather feedback, but respondents emphasized that the feedback space must be designed with the needs of the end-users in mind so that participation is maximized (C01; C02; C03; C04) and the potential for reaching incorrect assumptions, which [27] warned about, are reduced. In smaller partnerships, informal feedback structures were implemented, which helped to embed the co-creation process in the reality of the intended end-users (C26; C27). Respondents reported differing degrees of success, with the more successful pointing out that feedback structures conveyed trust and ownership of the partnerships by the 
end-users (C05; C17) and served to ensure that stakeholders knew that they were seen as peers and that their opinions were appreciated (C06; C07), thereby establishing the knowledge-sharing structures demanded by [26]. Trust in the partnerships and ownership of the innovations was particularly evident in projects with formal feedback structures (C12; C14; C17; C26).

A particular challenge for multi-actor co-innovation partnerships seeking to establish structures for interacting with external stakeholders is to decide who is external to partnerships that are often changing in form, with fluid boundaries (C02; $\mathrm{C} 05 ; \mathrm{C} 12 ; \mathrm{C} 13$; $\mathrm{C} 18$; C24). Indeed, external stakeholders can engage with a partnership and become internal partnership members (C18: C19; C23; C29), while other partners can leave their roles in a partnership but continue to interact $(\mathrm{C} 12 ; \mathrm{C} 13)$. Although the distinction may appear trivial, there are implications about the skills and structures needed to facilitate the interactions, and in some partnerships, there was disagreement about which structures were appropriate (C02; C06). This reflects the findings of [28] who point out the need to structure ideas so that alternative views of how partnerships learn and innovate are considered in conceptual frameworks. Especially larger partnerships seeking to engage with geographically, culturally, and/or professionally diverse stakeholders faced the challenge of simultaneously using multiple communication strategies to meet their varied needs (C01; C02; C06), and so could not adopt dominant ideas from other contexts [28].

Communication with varied stakeholders was easier when they shared a common interest or goals than when the culture, language, or geographic location were shared but the interests or goals diverged (C11; C16; C24). However, sometimes conflicts in goals surprisingly appeared with external stakeholders who were expected to voluntarily engage with partnerships (C02; C07; C08; C10). This was particularly the case with larger partnerships that had been written by a small core group and suggests that there had been insufficient consultation with the target groups during the proposal phase ( $01 ; \mathrm{C} 05 ; \mathrm{C} 12)$. This highlights the need to give separate consideration to local network embeddedness for co-innovation so that the dynamics of innovation networking are accounted for in innovation project planning and design [27].

Other partnerships found it relatively easy to find common goals, which led to engagement by and interaction with external stakeholders, which was especially the case when participatory methodologies were used (C04; C08; C09). A further enabling factor in communication was the membership of an existing network/CoP, in which common goals and interests had already been established (C04; C11; C13). However, this was perceived to be restrictive to new entrants and particularly to smaller organizations with smaller networks (C04), unless structures are explicitly established to include them (C09).

Communication with and the inclusion of external stakeholders required specific communication and facilitation skills, which can range from having knowledge of interdisciplinary methodologies (C04; C28) to simply being able to translate industry jargon into an understandable language (C01; C07; C20). Networks tended to be created from people with complementary industry skills and knowledge (C03; C17; C20; C22), with less emphasis placed on organizational, facilitation, or communication skills (C09; C18; C23). In cases in which these skills were not readily available, one means of including external stakeholders was to employ innovation brokers to build interpersonal relationships with potentially interested people (C13; C15; C19; C20; C22; C23) so that the partnership, with its goals, could be aligned within the prevailing cultures of the organizations on which the partnership depends for success [23]. An overview of the key findings with regard to interactions between external stakeholders and multi-actor co-innovation partnerships is shown in Table 4. 
Table 4. Overview of key findings for interactions with external stakeholders.

\begin{tabular}{|c|c|c|c|}
\hline Main Findings & Enabling Structures & Functions/Challenges & Overcoming Challenges \\
\hline $\begin{array}{l}\text { Engaging with external } \\
\text { stakeholders or other } \\
\text { partnerships can be driven by } \\
\text { both top-down considerations, } \\
\text { for example, funding } \\
\text { requirements and more } \\
\text { voluntary initiatives. } \\
\text { Interactions with end-users } \\
\text { need to be structured based } \\
\text { upon their needs, while } \\
\text { formalised feedback } \\
\text { structures foster end-user } \\
\text { trust and ownership. }\end{array}$ & $\begin{array}{l}\text { Explicit and effective network } \\
\text { coordination often taken up } \\
\text { by coordinator or } \\
\text { coordinating team. } \\
\text { Both in formal and informal } \\
\text { feedback structures, trust in } \\
\text { the partnership, and } \\
\text { ownership over outcomes are } \\
\text { key. }\end{array}$ & $\begin{array}{l}\text { Engaging with geographically, } \\
\text { culturally, and/or } \\
\text { professionally diverse } \\
\text { stakeholders. } \\
\text { Setting the boundaries of the } \\
\text { partnership: who is a partner } \\
\text { and who is a stakeholder. } \\
\text { Requires a specific set of } \\
\text { communication and } \\
\text { facilitation skills. }\end{array}$ & $\begin{array}{l}\text { Building a shared or common } \\
\text { interest or goal amongst } \\
\text { stakeholders through } \\
\text { sufficient consultation. } \\
\text { Engaging with pre-existing } \\
\text { networks or CoPs facilitates } \\
\text { stakeholder involvement. } \\
\text { If the necessary skills for } \\
\text { stakeholder engagement are } \\
\text { not available within a } \\
\text { partnership, these can be } \\
\text { employed by the engagement } \\
\text { of an innovation broker. }\end{array}$ \\
\hline
\end{tabular}

\subsection{Interactions with the Context/Environment}

Structures that enable the interaction between multi-actor co-innovation partnerships and their context include the existence of networks or connections that support knowledge exchange. These seem to be helpful for those partnerships that work on subjects on which a lot of knowledge is already available, where there is agreement on the key issues (C01; C11), or where these networks have a long history and have proved to be working well (C14; C21; 23). Furthermore, the socio-cultural and political beliefs of a country or sector play a large role in supporting the continuity of these networks. For example, a large amount of social trust, a mutual understanding, shared cultural values, or a clear overarching societal or economic objective are supportive factors $(\mathrm{C} 14 ; \mathrm{C} 15 ; \mathrm{C} 16 ; \mathrm{C} 17 ; \mathrm{C} 21 ; \mathrm{C} 23$; $\mathrm{C} 27)$, while the absence of these beliefs works counterproductively (C10; C17; C20; C29; C30). The authors of [18] argue that this fragmentation of visions can lead to conflicts between the various actors in society, thus constraining social learning and activities in innovation networks. When different policy frameworks or instruments appear incompatible, this complicates the co-innovation process. Especially in those cases where two policy goals (e.g., the ecological and the economical) actively conflict, this has a negative impact (C01; C06). The absence of legal frameworks, on the contrary, can play both to the advantage or disadvantage of the partnerships. For example, the lack of any support or willingness from the administration can complicate the implementation of certain activities (C01, C06; $\mathrm{C} 10$; $\mathrm{C20}$ ), while there are also examples where there was no legal or economic context yet, but where the broader society was supportive to what the multi-actor partnerships were working on (C07; C09; C15; C11; C19; C26; C28). This latter finding underpins that multi-actor co-innovation partnerships can have an empowering effect and have the potential to develop and "negotiate their own narrative", as also described by [12].

It was already mentioned that the complexity or novelty of a certain problem or topic has an impact on how the context influences the functioning of multi-actor coinnovation partnerships. Working on problems that are more contested was often found to be challenging. When this is combined with a certain degree of disagreement on the precise understanding of the problem, tunnel vision, or "lock-ins of the mind", the cocreation or cooperation between different actors is hampered (C01; C02; C04; C09). Other challenges created by the context are related to economic and market conditions that provide barriers, such as the lack of availability of funding with lower administrative requirements (C21; C28). However, economic and market conditions play a role, such as the degree of competitiveness and the power dynamics within an economic sector $(\mathrm{C} 07, \mathrm{C} 10, \mathrm{C} 15 ; \mathrm{C} 21)$. The authors of [18] argue that this increased competition between different types of knowledge providers creates an environment that is not conducive to the formation of innovation networks. For example, if there is no common external threat or risk and a high degree of competitiveness, actors are more careful in sharing experiences or 
knowledge than in cases where cooperation is perceived to bring more economic benefits (C15; C21).

Even in a challenging context, skilled and experienced actors are able to make a difference. Entrepreneurship and the ability to engage with different types of actors and facilitate conversations between them are identified as key skills, and these are closely related to actors' personalities ( $133 ; \mathrm{C} 20 ; \mathrm{C} 28)$. The lack of these skills or the perception that certain types of actors or organizations do not have these can form effective barriers to multi-actor co-innovation partnerships' functioning $(\mathrm{C} 07 ; \mathrm{C} 09)$. The relation between the actors of the partnerships and the national or regional context also plays a role in the way results of the co-innovation process are shared (C02; 24 ; 228$)$. For example, if a multi-actor partnership identifies themselves as providing an alternative to mainstream beliefs, this becomes a motivating factor for the success of the co-innovation process, as they would like to bring about change to the existing context, yet on the other hand, it can also create tension with other actors (C24; C28). However, in areas where actors are less experienced, more guidance from policy frameworks could be needed (C19). An overview of the key findings with regard to interactions between contextual environment and multi-actor co-innovation partnerships is shown in Table 5.

Table 5. Overview of key findings for interactions with the context/environment.

\begin{tabular}{|c|c|c|c|}
\hline Main Findings & Enabling Structures & Functions/Challenges & Overcoming Challenges \\
\hline $\begin{array}{l}\text { Multi-actor co-innovation } \\
\text { partnerships cover different } \\
\text { formal and informal } \\
\text { environments. } \\
\text { Both formal rules and } \\
\text { informal social factors } \\
\text { influence the acceptance or } \\
\text { openness of a context to } \\
\text { innovations, innovative ideas, } \\
\text { or new ways of cooperation. }\end{array}$ & $\begin{array}{l}\text { Access to and the availability } \\
\text { of pre-existing networks in } \\
\text { support of knowledge } \\
\text { exchange. } \\
\text { Socio-cultural and political } \\
\text { beliefs in support of } \\
\text { co-innovation processes } \\
\text { combined with a lot of social } \\
\text { trust. } \\
\text { Complementary policy } \\
\text { frameworks or the willingness } \\
\text { to support their improvement. }\end{array}$ & $\begin{array}{l}\text { Subjects that are complex, } \\
\text { contested, or novel, and have } \\
\text { disagreement on the problem } \\
\text { description. } \\
\text { Tunnel vision or lock-ins of } \\
\text { the mind. } \\
\text { Poor access or availability of } \\
\text { suitable funding } \\
\text { opportunities. } \\
\text { Economic and market } \\
\text { conditions unfavourable to } \\
\text { knowledge-sharing (e.g., } \\
\text { competitiveness, lack of } \\
\text { resources). }\end{array}$ & $\begin{array}{l}\text { Skilled and/or experienced } \\
\text { actors can make a difference. } \\
\text { The perception of the position } \\
\text { the partnership has in a given } \\
\text { context can ease or exacerbate } \\
\text { challenges. } \\
\text { Clear and guiding policy } \\
\text { frameworks. }\end{array}$ \\
\hline
\end{tabular}

\subsection{Interactions with Societal Challenges}

Within the 30 case studies, some of the multi-actor co-innovation partnerships were set up to seize a funding opportunity rather than being a direct response to a particular need. Indirectly, the funding opportunity has been called into existence as a consequence of demands set by society, which have, in their turn, been translated into policy objectives (C10; C06; C07; C09; C08; C11; C28). Particularly for more complex issues, such as environmental or socio-economic problems, policymakers drafting funding opportunities form important incentives for the development of innovative solutions aimed at tackling these challenges. Especially those cases where these broader concerns are tackled in combination with the provision of more direct tangible benefits to individual actors are positively evaluated in terms of their impacts (C12; C23; C26).

However, the impressions of how results of co-innovation processes are fed back into policy and, consequently, funding opportunities, are mixed, ranging from positive experiences, where this has led to more (political) attention for certain issues over instances where a large discrepancy remains between what is supported at the policy level and what is actually required in practice $(\mathrm{C} 01 ; \mathrm{C} 03 ; \mathrm{C} 22)$. This increased focus on short term results and the lack of stability in funding for certain areas has been related to the increased accountability of politicians and civil servants in terms of public investments [18]. This has increased the importance of the motivation or aspirations of the actors within the multi-actor co-innovation partnerships (C01), for example, when they are clearly driven 
by a desire to bring about change in the system (C22; C28). How actors perceive their wider impact on society often includes references to economic or environmental results. The case studies indicate that it is easier to reflect on or assess their impact when their partnership had clear-cut objectives or goals or when there was a policy framework as a base of comparison (C04; C08; C10; C11; C13; C14; C15; C16; C17; C19; C26). Additionally, the clarity and quality of the problem description and having a clear plan of activities supported actors in the partnerships in evaluating the impact of their cooperation.

Furthermore, the perception of the outcomes changes depending on the type of actors questioned (C24; C29). That which is a successful or positive impact for one actor might be negatively evaluated by another. Finally, the impacts of multi-actor co-innovation partnerships have been described on two levels, the level of the individual actors and the level of the broader society $(\mathrm{C} 04 ; \mathrm{C} 07 ; \mathrm{C} 08 ; \mathrm{C} 10)$. While the first level is rather straightforward for actors to identify, for example, a reduction of costs, more employees on the farm, or a new product on the market, the second level is more difficult to assess. In most case studies, these higher-level impacts at the societal level have been described as follows: a change in mindset, empowerment of a certain type of actor, or a shift towards a more environmentally friendly way of production $(\mathrm{C} 04 ; \mathrm{C} 07 ; \mathrm{C} 10 ; \mathrm{C} 26 ; \mathrm{C} 28 ; \mathrm{C} 29)$. This requires an understanding of a causal chain, or how their actions or outputs indirectly lead to other impacts. Nevertheless, this difficulty in assessment might also be related to the overrepresentation of EU-funded partnerships in the sample, which, following [46], are more likely to be focused on short term results rather than long-term objectives. An overview of the key findings with regard to interactions between societal challenges and multi-actor co-innovation partnerships is shown in Table 6.

Table 6. Overview of key findings for interactions with societal challenges.

\begin{tabular}{llll}
\hline Main Findings & Enabling Structures & Functions/Challenges & Overcoming Challenges \\
\hline $\begin{array}{l}\text { Partnerships' perceptions on } \\
\text { their contributions to societal } \\
\text { change. }\end{array}$ & $\begin{array}{l}\text { Policy strategies can } \\
\text { incentivise funding and thus, } \\
\text { Time for self-reflection and }\end{array}$ & $\begin{array}{l}\text { Discrepancies exist between } \\
\text { policy priorities and practical }\end{array}$ & $\begin{array}{l}\text { Motivations and aspirations } \\
\text { of partnerships. }\end{array}$ \\
$\begin{array}{l}\text { policy feedback is often } \\
\text { lacking. }\end{array}$ & $\begin{array}{l}\text { Direct and tangible impacts at } \\
\text { the individual level are easily }\end{array}$ & $\begin{array}{l}\text { Lack of vocabulary to } \\
\text { impacts of co-innovation on }\end{array}$ & $\begin{array}{l}\text { Combining socio-economic } \\
\text { and environmental benefits at } \\
\text { both the individual and } \\
\text { societal level. }\end{array}$ \\
\hline
\end{tabular}

\section{Conclusions}

The aim of creating the analytical framework was to facilitate the collection and analysis of data when studying multi-actor co-innovation partnerships, gain and ensure a common understanding of key concepts and relevant issues for studying multi-actor co-innovation partnerships, and build a basis for comparison between different types of multi-actor co-innovation partnerships. The framework, based on the five distinct types of interactions, proved to be an effective tool for conducting the comparative analysis of the 30 divergent case studies, as it enabled the identification of common patterns in terms of enabling structures, functions, or challenges, and how they are able to overcome challenges.

Interactions with funding bodies were reported to be quite complicated with a range of inflexible formal requirements and a perceived need by partners of the multi-actor partnerships to align the goals of their proposals with the goals of the funding bodies, which are often not clearly defined. This leads to partnerships adapting their proposals from what they want to do to what they perceive is wanted, and sometimes to overpromising expected outputs in an effort to win scarce funding. The inclusion of an experienced proposal writer in a partnership was recommended, and capable or well-functioning national and local contact points can also help. Larger organizations with sufficient human and financial resources were perceived to be advantaged and a lack of resources to prepare applications 
excludes smaller, but sometimes dynamic and innovative, organizations, although seed money was sometimes available for proposal writing.

Internal interactions within multi-actor co-innovation partnerships bring together people with common interests and complementary skills from a range of professional backgrounds and sometimes different cultural backgrounds. The diversity within partnerships was commonly seen as a strength, although it also brought some challenges to overcome. Communication difficulties due to background differences, a lack of ownership of the partnership leading to disengagement, and self-doubts about individuals' abilities to work within a multi-actor co-innovation partnership were among the challenges that needed to be addressed by the coordinator (or coordination team). Facilitation skills and experience were the key capacities needed to create a collaborative working environment that enables a process of co-learning, reflection, and trust-building over time.

A further challenge for coordinators of multi-actor co-innovation partnerships is to manage interactions with external stakeholders and other partnerships, which is analogous to networking and was typically top-down "embeddedness by design". Key challenges included insufficient consultation in the project design phase, leading to divergent goals and sometimes disagreement about the appropriate structures. The use of existing multiactor platforms, such as online forums and/or formal networks or associations, was found to be a useful strategy that could be complemented by building informal feedback structures on a personal level. Connecting to smaller organizations with smaller and/or distant networks was particularly challenging, and explicit and deliberate efforts were recommended to reach them to embed innovation in the reality of potential end-users.

Multi-actor co-innovation partnerships interact with formal and informal environments, and different formal rules and informal social factors influence the acceptance or openness of a context to innovations, innovative ideas, or new ways of cooperation. The main challenges included disagreements on the problem description and tunnel vision, which were particularly the case for topics that are complex, contested, or novel. Furthermore, economic and market conditions are often unfavourable to knowledge-sharing due to competition for scarce resources. Key structures and capacities to overcome these challenges included the access to and the availability of pre-existing networks in support of knowledge exchange, socio-cultural and political beliefs in support of co-innovation processes combined with a lot of social trust, which in turn, required skilled and experienced project coordinators, and clear and guiding policy frameworks.

The main challenges for a partnership in the interactions with challenges at the societal level were related to discrepancies between policy priorities and practical needs and the lack of an adequate vocabulary to evaluate diffuse, long-term impacts of co-innovation on the societal level. Time for self-reflection and policy feedback is often lacking in projects, and partnerships are often uncertain in their perceptions of their contributions to societal change. Policy strategies that can incentivize funding and thus, cooperation on more complex issues are needed, along with tools to evaluate direct and tangible impacts at the individual level. These could capitalize on the motivations and aspirations of partnerships to combine socio-economic and environmental benefits at both the individual and societal levels.

Although these results support the logic behind the analytical framework, and many of these results would have remained elusive without it, the study also had some limitations. The sample size of 30 case studies from the very many that were initially identified was relatively small and included many partnerships that receive funding from EU sources, so further study with a larger sample and a different mix of types of partnerships could shed more light on the enablers and barriers. On the other hand, the sampling strategy, based on maximum variety, suggests that the results might be generalizable to other multi-actor coinnovation partnerships [47]. A further limitation of the study is the sampling bias due to only including existing multi-actor co-innovation partnerships in the sample, which means they had overcome the barriers to establishment, such as gaining funding. Further insight may have been gained had failed multi-actor co-innovation partnerships been identified 
and included in the sample. Despite these weaknesses, the richness of the collected data, combined with the agreement with the available, although limited, literature allows a degree of confidence in the results. As we have posited, the multi-actor co-innovation partnerships have both characteristics of CoPs and innovation networks so as to be able to draw upon a wide body of knowledge. This choice has facilitated the comparison and identification of patterns common across the wide variety of multi-actor partnerships, and findings in the different interactions appear to be in line with and complement studies on both CoPs and innovation networks.

The goal of this study was to create an analytical framework that could be used to provide structure to data collection and enable the analysis of a particular type of cooperation, namely multi-actor co-innovation partnerships. The overarching objective was to have results that are both pertinent to each individual in-depth case study and facilitate a comparison between them. We found multi-actor co-innovation partnerships to have both characteristics of CoPs and innovation networks, which enabled us to develop a novel analytical framework drawing on both bodies of knowledge. By structuring the data collection according to the five interactions of the analytical framework, we were able to achieve this goal with a set of 30 divergent case studies that would otherwise have been exceedingly difficult to analyse and compare. For each of the interactions, we developed a separate set of questions to shape the analysis of structures and capacities and how these combine to overcome challenges while providing a great deal of flexibility about how the questions were answered. By providing this structured way of data presentation, while allowing sufficient flexibility in data collection to cater to the wide divergence in the case studies, we could accommodate the sometimes significant cultural, professional, or geographic differences between the case studies.

The outcome of this approach was that we could gain an overview of each case in detail while collecting sufficient and manageable data for cross-case study comparison. The application of the framework to the 30-case study of multi-actor co-innovation partnerships enabled the collation of insights into factors that enable or hinder them in achieving their goals. In this way, this analytical framework appears to be a promising tool to support the evaluation of multi-actor co-innovation partnerships and may also be applicable to wider forms of communities of practice. As [7] stated collaboration to be a necessary condition for innovation, these enhanced insights into the dynamics of multi-actor co-innovation partnerships potentially form an essential piece in the larger puzzle of how to best support the ability to adapt to rapidly changing conditions of not only farmers but the wide range of actors who are part of the farming system.

Author Contributions: Conceptualization, E.C., S.F., E.R. and R.H.; methodology, E.C., S.F., E.R. and R.H.; formal analysis, E.C. and R.H.; investigation, E.C., S.F. and R.H.; writing-original draft preparation, E.C. and R.H.; writing-review and editing, S.F. and E.R.; supervision, E.R.; project administration, E.R.; funding acquisition, E.R. All authors have read and agreed to the published version of the manuscript.

Funding: This research was funded by the European Commission, grant agreement ID: 773418.

Institutional Review Board Statement: Ethical review and approval for this study were granted by the LIAISON project ethics committee, which was established in accordance with the European Commission, grant agreement ID: 773418.

Informed Consent Statement: Informed consent was obtained from all subjects involved in the study and all data were handled in accordance with the GDPR.

Data Availability Statement: Data reported in this article may be made available on request providing the rights of respondents can be guaranteed in accordance with the GDPR.

Acknowledgments: The research conducted in this submission was conducted within the EU-H2020 project "LIAISON". The contents of this publication do not necessarily reflect the position or opinion of the European Commission. We are grateful to our LIAISON colleagues for their support in the data collection and their considerable intellectual inputs into understanding the context and nuance of 
the insights. Furthermore, we could like to thank the anonymous reviewers for their thoughtful and considered comments on a previous draft of this paper. We are also grateful to the representatives of the case study multi-actor co-innovation partnerships who freely gave their time.

Conflicts of Interest: The authors declare no conflict of interest.

\section{References}

1. Gomez, E.; Abrantes, P.; Banos, A.; Rocha, J.; Buxton, M. Farming under urban pressure: Farmers' land use and land cover change intentions. Appl. Geogr. 2019, 102, 58-70. [CrossRef]

2. Darnhofer, I. Farm resilience in the face of the unexpected: Lessons from the COVID-19 pandemic. Agric. Hum. Values 2020, 37, 605-606. [CrossRef] [PubMed]

3. Tully, K.; Ryals, R. Nutrient cycling in agroecosystems: Balancing food and environmental objectives. Agroecol. Sustain. Food Syst. 2017, 41, 761-798. [CrossRef]

4. Meuwissen, M.; Feindt, P.H.; Spiegel, A.; Termeer, C.J.A.M.; Mathijs, E.; De Mey, Y.; Finger, R.; Balmann, A.; Wauters, E.; Urquhart, J.; et al. A framework to assess the resilience of farming systems. Agric. Syst. 2019, 176, 102656. [CrossRef]

5. Morel, K.; Revoyron, E.; San Cristobal, M.; Baret, P.V. Innovating within or outside dominant food systems? Different challenges for contrasting crop diversification strategies in Europe. PLoS ONE 2020, 15, e0229910. [CrossRef] [PubMed]

6. Maidl, E.; Bresch, D.N.; Buchecker, M. Social integration matters: Factors influencing natural hazard risk preparedness-a survey of Swiss households. Nat. Hazards 2021, 105, 1861-1890. [CrossRef]

7. Awan, U.; Nauman, S.; Sroufe, R. Exploring the effect of buyer engagement on green product innovation: Empirical evidence from manufacturers. Bus. Strategy Environ. 2020, 30, 463-477. [CrossRef]

8. Wenger, E.C.; Snyder, W.M. Communities of Practice: The Organizational Frontier. Harv. Bus. Rev. 2000, 78, 139-146.

9. Schneider, F.; Ledermann, T.; Fry, P.; Rist, S. Soil conser- vation in Swiss agriculture-Approaching abstract and symbolic meanings in farmers' life- worlds. Land Use Policy 2010, 27, 332-339. [CrossRef]

10. Vanclay, F. Social principles for agricultural extension to as- sist in the promotion of natural resource management. Aust. J. Exp. Agric. 2004, 44, 213-222. [CrossRef]

11. Krzywoszynska, A. Making knowledge and meaning in communities of practice: What role may science play? The case of sustainable soil management in England. Soil Use Manag. 2019, 35, 160-168. [CrossRef]

12. Dolinska, A.; d'Aquino, P. Farmers as agents in innovation systems. Empowering farmers for innovation through communities of practice. Agric. Syst. 2016, 142, 122-130. [CrossRef]

13. Fieldsend, A.F.; Cronin, E.; Varga, E.; Biró, S.; Rogge, E. Sharing the space' in the agricultural knowledge and innovation system: Multi-actor innovation partnerships with farmers and foresters in Europe. J. Agric. Educ. Ext. 2021, 1-20. [CrossRef]

14. Ingram, J.; Gaskell, P.; Mills, J.; Dwyer, J. How do we enact co-innovation with stakeholders in agricultural research projects? Managing the complex interplay between contextual and facilitation processes. J. Rural. Stud. 2020, 65-77. [CrossRef]

15. Fieldsend, A.F.; Cronin, E.; Varga, E.; Biró, S.; Rogge, E. Organisational Innovation Systems for multi-actor co-innovation in European agriculture, forestry and related sectors: Diversity and common attributes. NJAS-Wagening. J. Life Sci. $2020,92$. [CrossRef]

16. Home, R.; Rump, N. Evaluation of a multi-case participatory action research project: The case of SOLINSA. J. Agric. Educ. Ext. 2015, 21, 73-89. [CrossRef]

17. Ingram, J.; Maye, D.; Kirwan, J.; Curry, N.; Kubinakova, K. Interactions between Niche and Regime: An Analysis of Learning and Innovation Networks for Sustainable Agriculture across Europe. J. Agric. Educ. Ext. 2015, 21, 55-71. [CrossRef]

18. Hermans, F.; Klerkx, L.; Roep, D. Structural Conditions for Collaboration and Learning in Innovation Networks: Using an Innovation System Performance Lens to Analyse Agricultural Knowledge Systems. J. Agric. Educ. Ext. 2015, 21, 35-54. [CrossRef]

19. Möller, K.; Halinen, A. Managing business and innovation networks-From strategic nets to business fields and ecosystems. Ind. Mark. Manag. 2017, 67, 5-22. [CrossRef]

20. Darnhofer, I.; Gibbon, D.; Dedieu, B. (Eds.) Farming Systems Research: An Approach to Inquiry. In Farming Systems Research into the 21st Century: The New Dynamic; Springer: Dordrecht, The Netherlands; Heidelberg, Germany; New York, NY, USA; London, UK, 2012; pp. 3-31. [CrossRef]

21. Darré, J.-P. Les hommes sont des réseaux pensants. Sociétés Contemp. 1991, 5, 55-66. [CrossRef]

22. Elzen, B.; Barbier, M.; Cerf, M.; Grin, J. Stimulating transitions towards sustainable farming systems. In Farming Systems Research into the 21st Century: The New Dynamic; Darnhofer, I., Gibbon, D., Dedieu, B., Eds.; Springer: Dordrecht, The Netherlands; Heidelberg, Germany; New York, NY, USA; London, UK, 2012; pp. 431-455. [CrossRef]

23. Acker, S.; Wagner, A. Feminist scholars working around the neoliberal university. Gend. Educ. 2019, 31, 62-81. [CrossRef]

24. Swan, J.; Newell, S.; Scarbrough, H.; Hislop, D. Knowledge management and innovation: Networks and networking. J. Knowl. Manag. 1999, 3, 262-275. [CrossRef]

25. Taddeo, R.; Simboli, A.; Ioppolo, G.; Morgante, A. Industrial Symbiosis. Networking and Innovation: The Potential Role of Innovation Poles. Sustainability 2017, 9, 169. [CrossRef]

26. Eggers, F.; Niemand, T.; Filser, M.; Kraus, S.; Berchtold, J. To network or not to network-Is that really the question? The impact of networking intensity and strategic orientations on innovation success. Technol. Forecast. Soc. Chang. 2020, 155, 119448. [CrossRef] 
27. Booyens, I.; Hart, T.G.B.; Ramoroka, K.H. Local Innovation Networking Dynamics: Evidence from South Africa. Eur. J. Dev. Res. 2018, 30, 749-767. [CrossRef]

28. Shearmur, R.; Carrincazeaux, C.; Doloreux, D. (Eds.) Handbook on the Geographies of Innovation; Edward Elgar: Cheltenham, UK, 2018.

29. Schut, M.; Klerkx, L.; Sartas, M.; Lamers, D.; Campbell, M.M.C.; Ogbonna, I.; Leeuwis, C. Innovation platforms: Experiences with their institutional embedding in agricultural research for development. Exp. Agric. 2016, 52, 537-561. [CrossRef]

30. Klerkx, L.; Seuneke, P.; de Wolf, P.; Rossing, W.A.H. Replication and translation of co-innovation: The influence of context in large international participatory research projects. Land Use Policy 2017, 61, 276-292. [CrossRef]

31. Flanagan, K.; Uyarra, E.; Laranja, M. The "policy mix" for innovation: Rethinking innovation policy in a multi-level, multi-actor context. Res. Policy 2011, 40, 702-713. [CrossRef]

32. Klerkx, L.; Aarts, N.; Leeuwis, C. Adaptive management in agricultural innovation systems: The interactions between innovation networks and their environment. Agric. Syst. 2010, 103, 390-400. [CrossRef]

33. Chandler, S. CSR-The Way Ahead or a Cul de Sac? In The ICCA Handbook on Corporate Social Responsibility; Pohl, M., Tolhurst, N., Eds.; John Wiley and Sons: Hoboken, NJ, USA, 2006; pp. 61-68.

34. Büttner, S.M.; Leopold, L.M. A 'new spirit' of public policy? The project world of EU funding. Eur. J. Cult. Political Sociol. 2016, 3, 41-71. [CrossRef]

35. Lamprinopoulou, C.; Renwick, A.; Klerkx, L.; Hermans, F.; Roep, D. Application of an integrated systemic framework for analysing agricultural innovation systems and informing innovation policies: Comparing the Dutch and Scottish agrifood sectors. Agric. Syst. 2014, 129, 40-54. [CrossRef]

36. Van Lancker, J.; Mondelaers, K.; Wauters, E.; Van Huylenbroeck, G. The Organizational Innovation System: A systemic framework for radical innovation at the organizational level. Technovation 2016, 52-53, 40-50. [CrossRef]

37. Ikeda, K.; Marshall, A. How successful organizations drive innovation. Strategy Leadersh. 2016, 44, 9-19. [CrossRef]

38. Klein Woolthuis, R.; Lankhuizen, M.; Gilsing, V. A system failure framework for innovation policy design. Technovation 2005, 25, 609-619. [CrossRef]

39. Hermans, F.; Stuiver, M.; Beers, P.; Kok, K. The distribution of roles and functions for upscaling and outscaling innovations in agricultural innovation systems. Agric. Syst. 2013, 115, 117-128. [CrossRef]

40. Larson, A. Sustainable innovation through an entrepreneurship lens. Bus. Strategy Environ. 2000, 9, 304-317. [CrossRef]

41. Evans, K.; Monterroso, I.; Ombogoh, D.B.; Liswanti, N.; Tamara, A.; Mariño, H.; Sarmiento, J.P.; Larson, A.M. Getting it Right, a Guide to Improve Inclusion in Multi-Stakeholder Forums; CIFOR: Bogor, Indonesia, 2021.

42. Wells, J.; Campbell, D.; Valacich, J.; Featherman, M. The effect of perceived novelty on the adoption of information technology innovations: A risk/reward perspective. Decis. Sci. 2010, 41, 813-843. [CrossRef]

43. Johnsson, M. The innovation facilitator: Characteristics and importance for innovation teams. J. Innov. Manag. 2018, 6, 1244. Available online: https://www.diva-portal.org/smash/get/diva2:1238414/FULLTEXT01.pdf (accessed on 3 June 2021). [CrossRef]

44. van Dijk, L.; Buller, H.; MacAllister, L.; Main, D. Facilitating practice-led co-innovation for the improvement in animal welfare. Outlook Agric. 2017, 46, 131-137. [CrossRef]

45. Howells, J. Intermediation and the role of intermediaries in innovation. Res. Policy 2006, 35, 715-728. [CrossRef]

46. Shepherd, J.; Ioannides, D. Useful funds, disappointing framework: Tourism stakeholder experiences of INTERREG. Scand. J. Hosp. Tour. 2020, 20, 485-502. [CrossRef]

47. Patton, M. Qualitative Evaluation and Research Methods; Sage: Beverly Hills, CA, USA, 1990; pp. 169-186. 